\title{
Photosynthetic responses of a wheat (Asakaze) - barley (Manas) 7H addition line to salt stress ${ }^{\star}$
}

\author{
D. SZOPKÓ* ${ }^{*}$ É. DARKÓ ${ }^{* *}$, I. MOLNÁR ${ }^{* *}$, K. KRUPPA ${ }^{* *}$, B. HÁLÓ* ${ }^{*}$ A. VOJTKÓ ${ }^{* * *}$, \\ M. MOLNÁR-LÁNG ${ }^{* *}$, and S. DULAI ${ }^{*+}$ \\ Department of Plant Physiology, Faculty of Science, Eszterházy University, H-3301 Eger, P.O. Box 43, Hungary* \\ Agricultural Institute, Centre for Agricultural Research, Hungarian Academy of Sciences, Martonvásár, \\ Brunszvik út 2, Hungary** \\ Department of Botany, Faculty of Science, Eszterházy University, H-3301 Eger, P.O. Box 43, Hungary ${ }^{* * *}$
}

\begin{abstract}
The photosynthetic responses to salt stress were examined in a wheat (Triticum aestivum L. cv. Asakaze) - barley (Hordeum vulgare L. cv. Manas) $7 \mathrm{H}$ addition line having elevated salt tolerance as compared to the parental wheat genotype. For this purpose, increasing $\mathrm{NaCl}$ concentrations up to $300 \mathrm{mM}$ were applied and followed by a 7-day recovery period. Up to moderate salt stress $(200 \mathrm{mM} \mathrm{NaCl})$, forcible stomatal closure, parallel with a reduction in the net assimilation rate $\left(P_{\mathrm{N}}\right)$, was only observed in wheat, but not in the addition line or barley. Since the photosynthetic electron transport processes of wheat were not affected by $\mathrm{NaCl}$, the impairment in $P_{\mathrm{N}}$ could largely be accounted for the saltinduced decline in stomatal conductance $\left(g_{\mathrm{s}}\right)$, accompanied by depressed intercellular $\mathrm{CO}_{2}$ concentration and carboxylation efficiency. Both, $P_{\mathrm{N}}$ and nonstomatal limitation factors $\left(\mathrm{L}_{\mathrm{ns}}\right)$ were practically unaffected by moderate salt stress in barley and in the addition line due to the sustained $g_{\mathrm{s}}$, which might be an efficient strategy to maintain the efficient photosynthetic activity and biomass production. At $300 \mathrm{mM} \mathrm{NaCl}$, both $P_{\mathrm{N}}$ and $g_{\mathrm{s}}$ decreased significantly in all the genotypes, but the changes in $P_{\mathrm{N}}$ and $\mathrm{L}_{\mathrm{ns}}$ in the $7 \mathrm{H}$ addition line were more favourable similar to those in wheat. The downregulation of photosynthetic electron transport processes around PSII, accompanied by increases in the quantum yield of regulated energy dissipation and of the donor side limitation of PSI without damage to PSII, was observed in the addition line and barley during severe stress. Incomplete recovery of $P_{\mathrm{N}}$ was observed in the addition line as a result of declined PSII activity probably caused by enhanced cyclic electron flow around PSI. These results suggest that the better photosynthetic tolerance to moderate salt stress of barley can be manifested in the $7 \mathrm{H}$ addition line which may be a suitable candidate for improving salt tolerance of wheat.
\end{abstract}

Additional key words: chlorophyll fluorescence induction; improved salt tolerance; leaf gas exchange; recovery; wheat-barley addition.

Received 25 January 2016, accepted 5 May 2016.

${ }^{+}$Corresponding author; e-mail: ds@ektf.hu

Abbreviations: $7 \mathrm{H}$ add - wheat-barley $7 \mathrm{H}$ addition line; $\mathrm{CEF}$ - cyclic electron flow around PSI; $C_{\mathrm{i}}$ - intercellular $\mathrm{CO}_{2}$ concentration; $\mathrm{F}$ - steady-state fluorescence; $\mathrm{F}_{0}, \mathrm{~F}_{\mathrm{m}}$ - minimum and maximum $\mathrm{Chl}$ fluorescence determined in the dark-adapted state; $\mathrm{F}_{\mathrm{m}}$ ' - maximal fluorescence in the light-adapted state; $\mathrm{F}_{\mathrm{v}}$ - variable fluorescence; $\mathrm{F}_{\mathrm{v}} / \mathrm{F}_{\mathrm{m}}$ - maximum quantum yield of PSII photochemistry; $g_{\mathrm{s}}$ - stomatal conductance; $\mathrm{L}_{\mathrm{ns}}$ - nonstomatal limitation; $\mathrm{L}_{\mathrm{s}}$ - stomatal limitation; NPQ - nonphotochemical quenching; $P_{0}-$ minimal P700 signal; $P_{\mathrm{m}}-$ maximal P700 level; $P_{\mathrm{m}}$ ' - maximal P700 signal in a given light state; $P_{\mathrm{N}}-$ net assimilation rate; $P_{\mathrm{Nmax}}-$ maximal assimilation rate; RuBP - ribulose-1,5-bisphosphate; RWC - relative water content; $\varepsilon$ - carboxylation efficiency; $\phi_{\mathrm{CEF}}-$ quantum yield of cyclic electron flow around PSI; $\phi \mathrm{NA}$ - quantum yield of the acceptor side limitation of PSI; $\phi \mathrm{ND}$ - quantum yield of the donor side limitation of PSI; $\phi_{\mathrm{NO}}$ - quantum yield of nonregulated energy dissipation; $\phi_{\mathrm{NPQ}}$ - quantum yield of regulated energy dissipation; $\phi$ PSI - effective quantum yield of photochemical energy conversion in PSI; $\phi$ PSII - effective quantum yield of photochemical energy conversion in PSII.

Acknowledgements: The authors wish to thank J. Prónay and R. Tarnai for their technical assistance. This work was supported by the Hungarian National Research Fund (K75466 and K112226), TÁMOP (4.2.2A-11/1/KONV-2012-0008), WHEALBI EU project and by a János Bolyai Research Scholarship from the Hungarian Academy of Sciences (for István Molnár).

\footnotetext{
- This paper was peer-reviewed and accepted for publication by the editors of the journal. It has not yet been copy-edited and formatted in the publication house style. Some modifications could appear in a final version of the paper. The paper can be cited using the authors'names, title, and DOI. After assignment of the final paper to an issue, the online-first version will be replaced by the final one.
} 


\section{Introduction}

Salinity is a problem in many parts of the world, not only on irrigated areas (Pitman and Läuchli 2002), but also on nonirrigated fields, reducing the growth and plant yield production through the shortening of lifetime of leaves. Considering that the maintained photosynthetic activity of leaves even under adverse salt stress conditions may contribute to the higher yield production (Munns 2002) hence it is necessary to develop crop varieties capable of sustaining photosynthesis even under saline conditions. Although both wheat and barley are considered to be glycophytes (Sanada et al. 1995), barley is regarded as being less sensitive to salt stress than cultivated wheat (Colmer et al. 2005, 2006) suggesting that they have different strategies for salt tolerance (Munns et al. 2006, Munns and Tester 2008).

Salinization is caused predominantly by $\mathrm{NaCl}$. Under saline conditions water availability decreases causing osmotic stress, but ionic stress also occurs if the ion components of $\mathrm{NaCl}$, especially $\mathrm{Na}^{+}$ions, reach a toxic level as reviewed by da Silva et al. (2011).

Photosynthesis is particularly sensitive to salinity (Sudhir and Murthy 2004, Ashraf and Harris 2013). The limitation of photosynthetic capacity takes place in two stages: (1) limitation associated with increased stomatal resistance, known as stomatal limitation (Centritto et al. 2003); (2) limitation due to nonstomatal disturbance mainly at high salt concentrations (James et al. 2002, Centritto et al. 2003, Munns et al. 2006, Stepien and Klobus 2006). The regulation of stomatal conductance $\left(g_{\mathrm{s}}\right)$ is an important physiological process leading to reduced water loss, and appears to be dominant at intermediate salinity levels (Everard et al. 1994). Closed stomata have both positive and negative effects on photosynthesis. Reduced $g_{s}$ may contribute to maintaining water content through a decreased transpiration rate, which could be favourable for minimizing $\mathrm{Na}^{+}$transport towards the shoots (Tester and Davenport 2003). At the same time, closed stomata causes a diffusion barrier resulting in a decrease in $\mathrm{CO}_{2}$ carboxylation (Flexas et al. 2004). On the other hand, the higher $g_{s}$ may lead to considerable carbon assimilation providing better growth rate and/or improved grain yield (James et al. 2008, Rahnama et al. 2010). Plants responding to osmotic or ionic stress with relative high $g_{s}$ are able to maintain their $\mathrm{CO}_{2}$ assimilation rate $\left(P_{\mathrm{N}}\right)$ more successfully compared to plants reacting with low $g_{s}$ (James et al. 2008, Dulai et al. 2010, 2011, 2014).

Salt stress has many consequences for nonstoma-dependent processes as well. Salt-induced nonstomatal inhibition $\left(\mathrm{L}_{\mathrm{ns}}\right)$ can be observed when $\mathrm{CO}_{2}$ assimilation is disturbed by the presence of toxic ions in the mesophyll cells. This limitation may be associated with limited Rubisco activity a reduced amount of Rubisco protein or poor efficiency of PSII in the second stage of salt stress (Muranaka et al. 2002, Kalaji et al. 2011), when a high concentration of toxic $\mathrm{Na}^{+}$and $\mathrm{Cl}^{-}$ions evolves in the leaves (Munns and Tester 2008). During salt stress photosynthesis is often hindered by the secondary effect of disturbed ion homeostasis. This often leads to the plant absorbing more light energy than can be used by $\mathrm{CO}_{2}$ fixation, which causes over-reduction of the linear electron transport chain leading to oxidative damage (Asada 2006). This may also contribute to suppressing the repair of PSII, resulting in photoinhibition (Allakhverdiev et al. 2002). Under these circumstances the downregulation of PSII by nonradiative energy dissipation is an essential defence mechanism (Qiu et al. 2003). It has also been reported that PSII is usually more sensitive to stress conditions than PSI (Apostolova et al. 2006). In fact, PSI activity may even be enhanced by salt as observed in cyanobacterium Spirulina platensis (Sudhir et al. 2005). Moreover, the higher quantum yield of PSI ( $\phi_{\text {PSI }}$ ) compared with that of PSII ( $\phi_{\text {PSII }}$ ) may favour the cyclic electron flow (CEF) around PSI. CEF may have a role in maintaining an adequate $\Delta \mathrm{pH}$ for nonphotochemical quenching (NPQ), which could act as a protective mechanism in the case of both osmotic (Golding and Johnson 2003) and $\mathrm{Na}^{+}$ionic stress (Lu et al. 2008). The ability to maintain better photosynthesis and consequently achieve higher growth and production/yield are based on these intensive protecting/regulating mechanisms during salt stress.

Recently, several new wheat barley addition lines have been developed using wheat cv. Asakaze and barley cv. Manas cultivars in order to increase the allelic variation of wheat (Molnár-Láng et al. 2012). It has recently been reported by Darkó et al. (2015), that among the added barley chromosomes tested $(2 \mathrm{H}, 3 \mathrm{H}, 4 \mathrm{H}, 6 \mathrm{H}, 7 \mathrm{H})$, the $7 \mathrm{H}$ addition line has elevated salt tolerance as compared to the wheat parent, and that the salt tolerance of the $7 \mathrm{H}$ addition line is associated with elevated osmotic adjustment capacity, similar to that found in Manas. However, except for a short preliminary study showing that increasing salt concentrations caused a less pronounced decline in net photosynthesis in the wheat (Asakaze)-barley (Manas) 7H addition line (7H add) than in the parental variety Asakaze (Dulai et al. 2010), the photosynthetic responses of this line, focusing to the role of photoprotective mechanisms and electron transport processes connected to PSII and PSI under salt treatment have not yet been studied in detail.

The aim of the present study was to clarify the effects of the added $7 \mathrm{H}$ barley chromosome on the photosynthetic processes under salt stress conditions using the $7 \mathrm{H}$ add line. For this purpose the salt stress responses of several parameters (gas exchange, chlorophyll $a$ fluorescence induction and P700) were examined and compared to those of the parental genotypes to obtain deeper knowledge on the mechanisms responsible for the salt tolerance of photosynthesis in this line. 


\section{Materials and methods}

Plant materials and treatments: The seeds of wheat cv. Asakaze (Japanese facultative), barley cv. Manas (Ukrainian six-row, winter) and the $7 \mathrm{H}$ wheat (Asakaze)-barley (Manas) addition line $(7 \mathrm{H}$ add) required for the experiments were provided by Márta Molnár-Láng, Agricultural Institute of the Hungarian Academy of Science (Martonvásár). The effects of salt stress were investigated on the $7 \mathrm{H}$ add developed from the Asakaze $\times$ Manas hybrid (Molnár-Láng et al. 2000, 2007, 2012), together with the parental lines.

The seeds were germinated on filter paper moistened with distilled water in Petri dishes for two days. The germinated seeds were grown in half-strength modified Hoagland nutrient solution (Nagy and Galiba 1995) in 1,500 ml pots in growth chambers with normal $\mathrm{CO}_{2}$ concentration, $75 \%$ relative humidity, a light intensity of $200 \mu \mathrm{mol} \mathrm{m}^{-2} \mathrm{~s}^{-1}$, a temperature of $20-25^{\circ} \mathrm{C}$ and $12 / 12 \mathrm{~h}$ of light/dark illumination. Salt stress was induced in five-week-old plants by applying increasing $(100,200$, and $300 \mathrm{mM})$ concentration of $\mathrm{NaCl}$ (Sigma, St. Louis, USA) in seven-day cycles. Measurements were made before the treatment (control), after each seven-day treatment and after two and seven days of regeneration without $\mathrm{NaCl}$. All the experiments were performed on intact leaves or leaf segments.

Fluorescence in situ hybridization: The presence of the added barley chromosome was checked using genomic in situ hybridization (GISH) on individual plants of the wheat-barley $7 \mathrm{H}$ disomic addition lines used for the physiological experiments (Fig. 1). Root tips collected from germinated seeds were fixed for chromosome preparations as described earlier (Molnár-Láng et al. 2000). Total barley genomic DNA was used as a probe and unlabelled wheat genomic DNA was used as blocking DNA. Labelling, in situ hybridization and detection were carried out as reported by Molnár-Láng et al. (2012). The slides were screened using a Zeiss Axio Imager M2 fluorescence microscope with the appropriate filter sets. Images were captured with a Zeiss AxioCam MRm CCD camera and processed with Zeiss Axiovision 4.8.2. software.

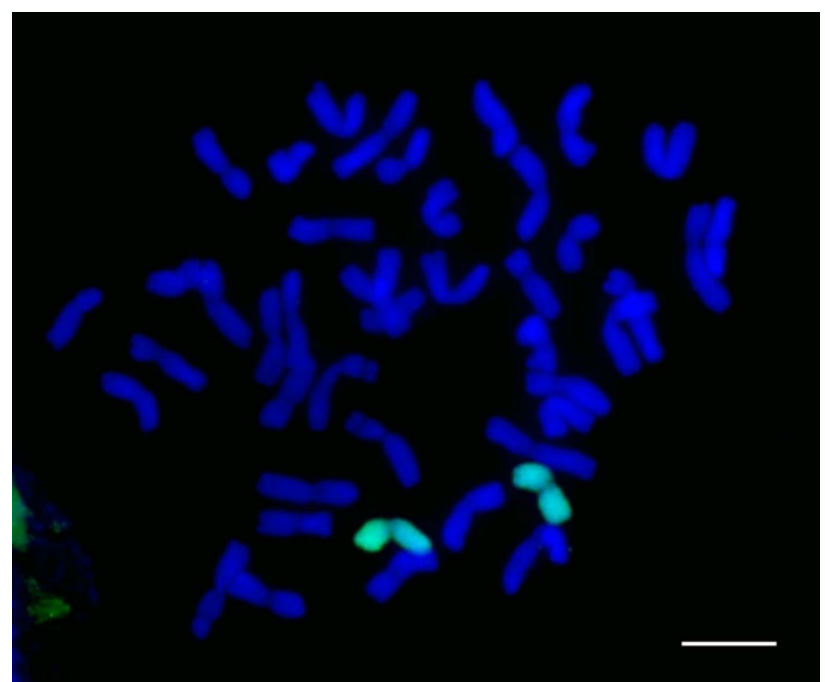

Fig. 1. Detection of the added $7 \mathrm{H}$ barley chromosomes in mitotic meristematic cells of an Asakaze-Manas disomic addition line (7H add) using GISH. Barley chromosomes were detected using total barley genomic DNA as a probe (labelled with biotin-16-dUTP and detected with streptavidin-FITC, green), wheat chromosomes are blue as a result of counterstaining with DAPI. Bar $=10 \mu \mathrm{m}$.

Chlorophyll fluorescence: The in vivo chlorophyll $a$ fluorescence was measured in dark-adapted intact leaves using a dual channel P700 and chlorophyll fluorescence measuring system (Dual PAM-100, Walz, Effeltrich, Germany) with DUAL-E and DUAL-DB measuring heads containing a PIN photodiode for detection. The initial level of fluorescence $\left(\mathrm{F}_{0}\right)$ was detected after 15-min dark adaptation. The maximal fluorescence level of the dark- $\left(\mathrm{F}_{\mathrm{m}}\right)$ and light- $\left(\mathrm{F}_{\mathrm{m}}{ }^{\prime}\right)$ adapted leaves were determined by applying saturating flashes $\left(15,000 \mu \mathrm{mol} \mathrm{m}^{-2} \mathrm{~s}^{-1}\right)$ lasting $0.8 \mathrm{~s}$. Photosynthesis was induced by continuous illumination of the leaf at $221 \mu \mathrm{mol} \mathrm{m} \mathrm{m}^{-2} \mathrm{~s}^{-1}$ for $15 \mathrm{~min}$. The fluorescence parameters were calculated as described by van Kooten and Snel (1990) and Klughammer and Schreiber (2008a) on the basis of the following equations: maximal quantum yield of PS II, $F_{v} / F_{m}=\left(F_{m}-F_{0}\right) / F_{m}$; effective quantum yield of PS II, $\phi_{\text {PSII }}=\left(F_{m}{ }^{\prime}-F\right) / F_{m}{ }^{\prime}=\Delta F / F_{m}{ }^{\prime}$; quantum yield of regulated energy dissipation, $\phi_{\mathrm{NPQ}}=\left(\mathrm{F} / \mathrm{F}_{\mathrm{m}}{ }^{\prime}\right)-\left(\mathrm{F} / \mathrm{F}_{\mathrm{m}}\right)$; quantum yield of nonregulated energy dissipation, $\phi_{\mathrm{NO}}=\mathrm{F} / \mathrm{F}_{\mathrm{m}}$. 
P700 measurements: P700 was measured simultaneously with chlorophyll fluorescence via changes in absorbance in the near infrared spectrum (difference signal measured at $875-830 \mathrm{~nm}$ ) as described by Klughammer and Schreiber (1994, 2008b) using the DUAL-E and DUAL-DB measuring heads equipped with a PIN photodiode and a special pulse preamplifier with maximal time resolution of $30 \mu \mathrm{s}$ for measuring P700. The complementary PSI quantum yields were calculated on the basis of the following equations: photochemical quantum yield of PS I, $\phi_{\mathrm{PSI}}=1-\left(\phi_{\mathrm{ND}}\right)-\left(\phi_{\mathrm{NA}}\right)$; nonphotochemical quantum yield of PSI, related to limitation on the donor side, $\phi_{\mathrm{ND}}=1-\mathrm{P} 700_{\text {red.; }}$; nonphotochemical quantum yield of PSI, related to limitation on the acceptor side, $\phi_{\mathrm{NA}}=\left(P_{\mathrm{m}}-P_{\mathrm{m}}{ }^{\prime}\right) / P_{\mathrm{m}}$. The yield of the cyclic electron flow around PSI was estimated from the difference between $\phi_{\text {PSI }}$ and $\phi_{\text {PSII }}, \phi_{\mathrm{CEF}}=\phi_{\mathrm{PSI}}-\phi_{\mathrm{PSII}}($ Huang et al. 2010).

Gas exchange: The $\mathrm{CO}_{2}$ assimilation of intact leaves was measured with an infrared gas analyser (GFS-3000FL, Walz, Effeltrich, Germany). The net assimilation rate $\left(P_{\mathrm{N}}\right)$, stomatal conductance $\left(g_{\mathrm{s}}\right)$ and intercellular $\mathrm{CO}_{2}$ concentration $\left(C_{\mathrm{i}}\right)$ were calculated in the light-saturated state of photosynthesis $\left(1,000 \mu \mathrm{mol} \mathrm{m} \mathrm{m}^{-2} \mathrm{~s}^{-1}\right)$ using the equations reported by von Caemmerer and Farquhar (1981). The gas exchange chamber parameters were $25^{\circ} \mathrm{C}, 20 \%$ relative humidity. The $\mathrm{CO}_{2}$ concentration of the reference air was $360 \mu \mathrm{L} \mathrm{L}^{-1}$. The maximal assimilation rate $\left(P_{\mathrm{Nmax}}\right)$ was determined at saturating light intensity $\left(1,000 \mu \mathrm{mol} \mathrm{m} \mathrm{m}^{-2}\right)$ and $\mathrm{CO}_{2}$ concentration $\left(1,200 \mu \mathrm{L} \mathrm{L}^{-1}\right)$. The response of $P_{\mathrm{N}}$ to changes in ambient $\mathrm{CO}_{2}$ concentration was measured between $0-1,200 \mu \mathrm{L} \mathrm{L}^{-1} \mathrm{CO}_{2}$ at the above mentioned conditions. $P_{\text {Nmax }}$ was determined at $1,000 \mu \mathrm{mol} \mathrm{m} \mathrm{m}^{-2} \mathrm{~s}^{-1}$ light intensity and $1,200 \mu \mathrm{L} \mathrm{L}^{-1} \mathrm{CO}_{2}$ concentration. The stomatal $\left(\mathrm{L}_{\mathrm{s}}\right)$ and nonstomatal $\left(\mathrm{L}_{\mathrm{ns}}\right)$ limitation were determined on the basis of $C_{\mathrm{i}} v . P_{\mathrm{N}}$ curves, as described by Lawlor (2002). The carboxylation efficiency $\left(\varepsilon, \mathrm{mol} \mathrm{CO}_{2}\right.$ $\mathrm{m}^{-2} \mathrm{~s}^{-1}$ ) was calculated as the initial slope of $C_{\mathrm{i}} v . P_{\mathrm{N}}$ curves according to Pfanz et al. (2007).

Determination of relative water content and dry matter production: The water status of the plants was traced by determining the relative water content (RWC) according to the following equation: $\mathrm{RWC}[\%]=[(\mathrm{FM}-\mathrm{DM}) /(\mathrm{SM}-\mathrm{DM})]$ $\times 100$, where FM is the fresh mass, SM is the water-saturated mass and DM is the oven dry mass. Fresh mass of the leaves was measured, after which they were dried at $105^{\circ} \mathrm{C}$ for $12 \mathrm{~h}$. To determine the water-saturated mass, the leaves were incubated in distilled water in a Petri dish for $24 \mathrm{~h}$ at room temperature. The shoot and root dry mass [g per plant] was determined on nine-week-old plants at the end of the whole experimental period and the data were compared with the values for control plants of same age, grown in Hoagland solution without $\mathrm{NaCl}$.

Statistical analysis: All the experiments were repeated three times. Four measurements were performed on each genotypes and treatment for chlorophyll fluorescence and P700 measurements, while five measurements were performed for $\mathrm{CO}_{2}$ gas exchange analyses. The RWC content was determined in five replicates of each genotypes and treatments. Biomass production was determined on 16 measurements per treatments.

The results are presented as the means \pm standard deviations (SD) of three independent experiments. Differences between treatments or genotypes within each treatment were determined by means of Tukey's post hoc test $(p \leq 0.05)$ using the SPSS 16.0 software (Table 1S, supplement available online).

\section{Results}

Genomic stability of the 7H Asakaze-Manas disomic addition line: As the wheat-barley addition lines have a certain level of genetic instability leading to the loss of barley chromosomes, it is needed to prove the presence of barley chromosome $7 \mathrm{H}$ in the experimental plants. By the use of total barley genomic DNA as probe for genomic in situ hybridization to the mitotic cells of $7 \mathrm{H}$ add, a pair of barley chromosome $7 \mathrm{H}$ were unambiguously detected. The GISH on the experimental population of the $7 \mathrm{H}$ add showed that $100 \%$ of the seeds contained the added barley chromosome pair (Fig. 1), so the photosynthetic response to the salt stress was not affected by the lack of barley chromosome in these plants.

Relative water content and gas-exchange parameters: The relative water content of the leaves decreased parallel with increasing salt concentration in all the genotypes (Fig. 2A). When $100 \mathrm{mM} \mathrm{NaCl}$ was applied, a decrease in RWC was observed in Asakaze and the $7 \mathrm{H}$ add line but further increases in salt concentration only resulted in a slight water loss. In the case of Manas, the decrease in RWC was not statistically significant up to $200 \mathrm{mM} \mathrm{NaCl}$ compared to the untreated control, but a great decline was observed at $300 \mathrm{mM}$. At this stage the difference between Manas and the other lines was statistically significant $(p \leq 0.05)$. In the regeneration period the genotypes recovered their water contents completely by the $7^{\text {th }}$ day.

The stomatal conductance $\left(g_{\mathrm{s}}\right)$ decreased in all the genotypes (Fig. $2 B$ ). The highest initial $g_{\mathrm{s}}$ and the strongest stomatal closure were detected in Asakaze. In this genotype the $g_{\mathrm{s}}$ value was only $46 \%$ of the control at $100 \mathrm{mM} \mathrm{NaCl}$, and this reduction in $g_{\mathrm{s}}$ continued as the salt concentration intensified. In contrast to Asakaze, the decrease in $g_{\mathrm{s}}$ was moderate in 


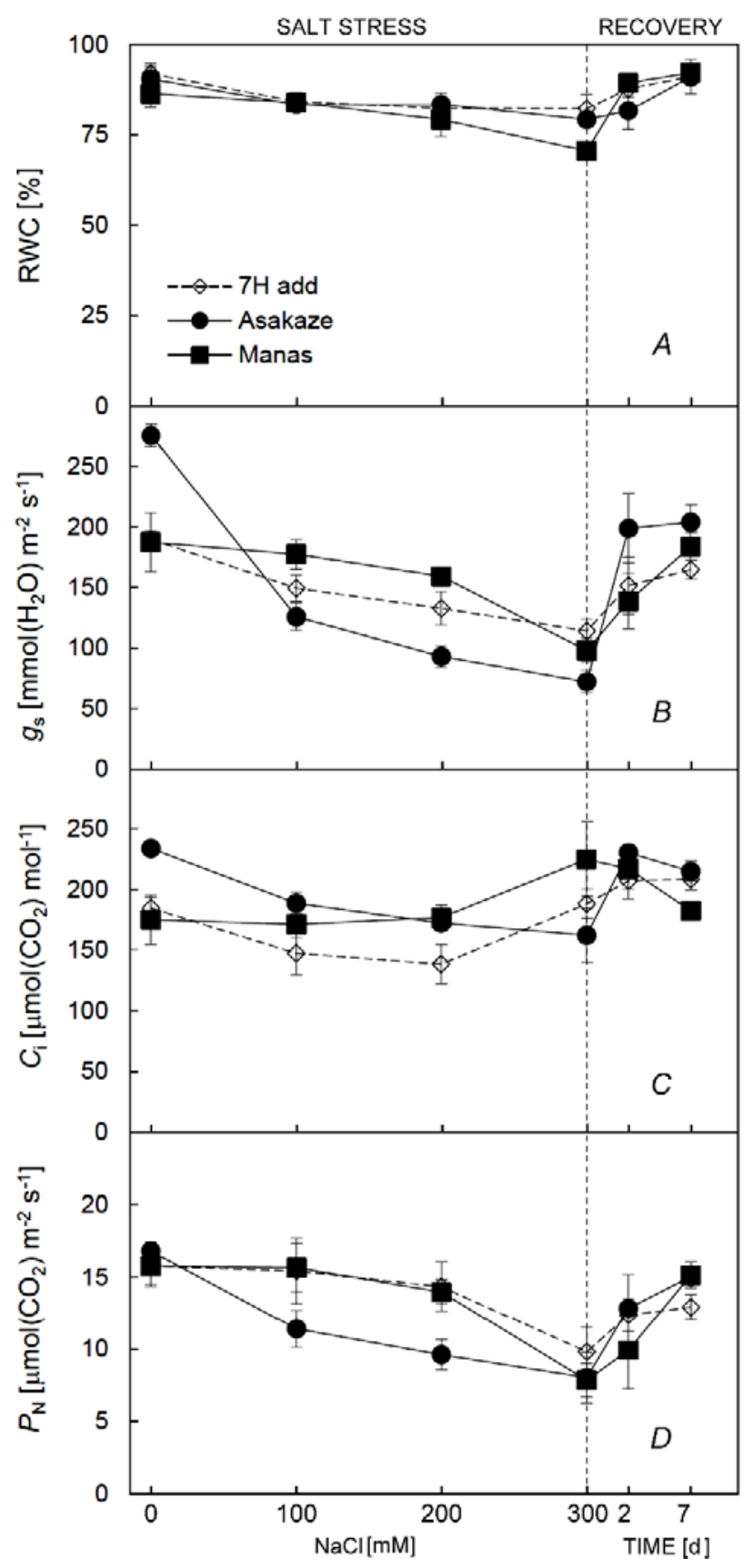

Fig. 2. Effects of increasing $\mathrm{NaCl}$ concentration followed by seven days of regeneration on relative water content (RWC) $(A)$, stomatal conductance $\left(g_{\mathrm{s}}\right)(B)$, intercellular $\mathrm{CO}_{2}$ concentration $\left(C_{\mathrm{i}}\right)(C)$, net assimilation rate $\left(P_{\mathrm{N}}\right)(D)$ in $7 \mathrm{H}$ wheat-barley addition line $(7 \mathrm{H}$ add $)$, wheat (Asakaze) and barley (Manas). Each value $( \pm \mathrm{SD})$ is the mean of the data of five plants per treatment.

barley and the $7 \mathrm{H}$ add up to $200 \mathrm{mM} \mathrm{NaCl}$, and the value of this parameter was still higher $(p \leq 0.01)$ than in Asakaze even at $300 \mathrm{mM} \mathrm{NaCl}$. Although, the absolute difference in the $g_{\mathrm{s}}$ values in the genotypes was not substantial at severe stress more than $70 \%$ of the original activity was lost in the case of Asakaze but less than $40 \%$ in the $7 \mathrm{H}$ add.

Like $g_{\mathrm{s}}$, the intercellular $\mathrm{CO}_{2}$ concentration $\left(C_{\mathrm{i}}\right)$ decreased continuously in Asakaze, as the salt stress became more severe but swiftly returned to the control level in parallel with the opening of the stomata during the recovery period (Fig. 2B,C). $C_{\mathrm{i}}$ was practically unaltered in Manas and decreased in the $7 \mathrm{H}$ add up to $200 \mathrm{mM} \mathrm{NaCl}$ and then increased significantly in both genotypes when the highest salt concentration was applied.

In respect to net assimilation rate $\left(P_{\mathrm{N}}\right)$ there was no significant difference between the untreated genotypes (Fig. $\left.2 D\right)$. Like $g_{\mathrm{s}}, P_{\mathrm{N}}$ decreased in Asakaze parallel with the salt treatment being significantly lower even at $100 \mathrm{mM} \mathrm{NaCl}(p \leq 0.05)$, while in the other lines the values remained close to the control level up to $200 \mathrm{mM} \mathrm{NaCl}$. In this $\mathrm{NaCl}^{\text {range }}$ the $\mathrm{CO}_{2}$ 
fixation values were significantly higher in Manas and the $7 \mathrm{H}$ add than in Asakaze $(p \leq 0.05)$. At a salt concentration of $200 \mathrm{mM}, P_{\mathrm{N}}$ was strongly inhibited in the latter genotype leading to the loss of more than $43 \%$ of the original activity. At the $300 \mathrm{mM} \mathrm{NaCl}$ level, $P_{\mathrm{N}}$ decreased more intensively in all the genotypes, and the differences between the genotypes were less been pronounced. During the regeneration period $P_{\mathrm{N}}$ was almost fully restored by the $7^{\text {th }}$ day in Asakaze and Manas, while the value was somewhat lower for $7 \mathrm{H}$.

The inhibition of $P_{\mathrm{N}}$ in Asakaze even at a moderate stress level suggests that the limitation of $\mathrm{CO}_{2}$ fixation in wheat might partly be due to other factors than in Manas and the $7 \mathrm{H}$ add. During salt stress the maximal assimilation rate $\left(P_{\mathrm{Nmax}}\right)$ determined at saturating light intensity $\left(1,000 \mu \mathrm{mol} \mathrm{m}{ }^{-2} \mathrm{~s}^{-1}\right)$ and $\mathrm{CO}_{2}$ concentration $\left(1,200 \mu \mathrm{L} \mathrm{L}^{-1}\right)$ decreased continuously in Asakaze while it was fully sustained up to $200 \mathrm{mM} \mathrm{NaCl}$ in Manas and the $7 \mathrm{H}$ add (Fig. 3A). More severe salt treatment $(300 \mathrm{mM})$ resulted in an inhibition of $P_{\mathrm{Nmax}}$ in all the genotypes. Parallel with the decrease in $P_{\mathrm{Nmax}}$ and the intensification

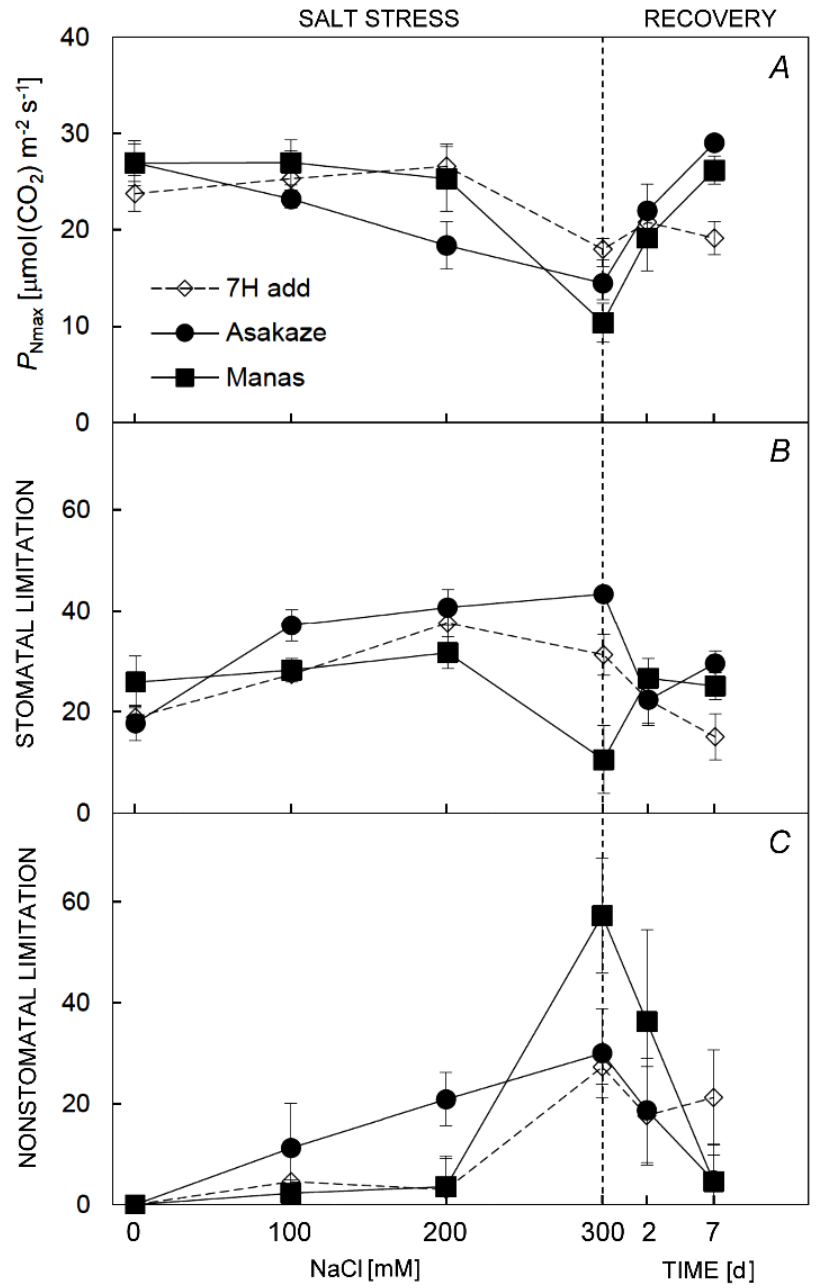

Fig. 3. Effects of increasing $\mathrm{NaCl}$ concentrations followed by seven days of regeneration on maximal assimilation rate measured at saturating $\mathrm{CO}_{2}$ level $\left(P_{\mathrm{Nmax}}\right)(A)$, stomatal limitation $(B)$, nonstomatal limitation $(C)$ in wheat-barley $7 \mathrm{H}$ addition line $(7 \mathrm{H}$ add), wheat (Asakaze) and barley (Manas). Each value $( \pm \mathrm{SD})$ is the mean of the data of five plants per treatment.

of salt stress, nonstomatal limitation $\left(\mathrm{L}_{\mathrm{ns}}\right)$ calculated on the basis of $C_{\mathrm{i}} v . P_{\mathrm{N}}$ curves increased continuously in Asakaze while it was negligible in Manas and the $7 \mathrm{H}$ add up to $200 \mathrm{mM} \mathrm{NaCl}$. At severe stress however, $\mathrm{L}_{\mathrm{ns}}$ was the highest in Manas, which contrasted strikingly with the other lines. When salt was removed from the medium $\mathrm{L}_{\mathrm{ns}}$ dropped to almost zero by the $7^{\text {th }}$ day with the exception of the $7 \mathrm{H}$ add. Stomatal limitation $\left(\mathrm{L}_{\mathrm{s}}\right)$ increased significantly in Asakaze and the $7 \mathrm{H}$ add at lower salt levels, and remaining almost unchanged in Manas (Fig. 3B,C). When the stress became more intensive $(300 \mathrm{mM} \mathrm{NaCl})$, however, $\mathrm{L}_{\mathrm{s}}$ dropped considerably for Manas in parallel with the dramatic rise in the nonstomatal limitation in this genotype.

The application of 100 and $200 \mathrm{mM} \mathrm{NaCl}$ caused no substantial change in the initial slope of the $C_{\mathrm{i}} v . P_{\mathrm{N}}$ curves, representing the maximal carboxylation efficiency $(\varepsilon)$, in Manas or the $7 \mathrm{H}$ add (Table 1). In Asakaze, on the other hand, 
there was a substantial reduction in $\varepsilon$ by the $200 \mathrm{mM} \mathrm{NaCl}$ level compared with the initial level and with the other two genotypes. A considerable decrease in $\varepsilon$ was observed when the strongest salt treatment was applied both in Manas and the $7 \mathrm{H}$ add. At this salt level Asakaze and the $7 \mathrm{H}$ add showed almost the same value, while $300 \mathrm{mM} \mathrm{NaCl}$ reduced $\varepsilon$ to half in Manas. The value of $\varepsilon$ recovered in wheat and barley, but the control level was not fully regained by the $7 \mathrm{H}$ add even on the $7^{\text {th }}$ day after salt removal.

Table 1. Effects of increasing $\mathrm{NaCl}$ concentrations followed by 7 days of regeneration on the carboxylation efficiency $\left(\varepsilon, \mathrm{mol} \mathrm{CO}_{2} \mathrm{~m}^{-2} \mathrm{~s}^{-1}\right)$ in the leaves of Asakaze, Manas and the $7 \mathrm{H}$ addition line (Asakaze - wheat, Manas - barley, $7 \mathrm{H}$ add - wheat-barley $7 \mathrm{H}$ addition line). $\varepsilon$ was calculated as the initial slope of $C_{\mathrm{i}} v$. $P_{\mathrm{N}}$ curves according to Pfanz et al. (2007). Each value ( $\left.\pm \mathrm{SD}\right)$ is the mean of the data of five plants per treatment. The asterisks indicate significant differences between untreated control and treatments within a genotype at $p \leq 0.05$ level. Nonsignificant differences between the untreated control and treatments are marked by ns. Different letters show significant differences from the other lines (a), between Manas and 7H add (b) and between Asakaze and 7H add (c) at $p \leq 0.05$ level within the same treatment.

\begin{tabular}{lllllll}
\hline Genotypes & Control & $\mathrm{NaCl}[\mathrm{mM}]$ & & \multicolumn{2}{l}{ Recovery [d] } \\
& & 100 & 200 & 300 & 2 & 7 \\
\hline Asakaze & $0.091 \pm 0.006$ & $0.079 \pm 0.007^{\text {ns }}$ & $0.068 \pm 0.003^{*}$, a & $0.062 \pm 0.002^{*}$ & $0.072 \pm 0.008^{*}$ & $0.087 \pm 0.004^{\text {ns, c }}$ \\
Manas & $0.090 \pm 0.010$ & $0.092 \pm 0.007^{\text {ns }}$ & $0.088 \pm 0.0025^{\text {ns }}$ & $0.045 \pm 0.009^{*}$ & $0.056 \pm 0.013^{*}, \mathrm{~b}$ & $0.085 \pm 0.005^{\text {ns }}$ \\
7H add & $0.084 \pm 0.007$ & $0.097 \pm 0.008^{\text {ns }}$ & $0.097 \pm 0.015^{\text {ns }}$ & $0.059 \pm 0.007^{*}$ & $0.070 \pm 0.006^{\text {ns, b }}$ & $0.068 \pm 0.006^{\text {ns, c }}$ \\
\hline
\end{tabular}

Chlorophyll a fluorescence induction and P700 parameters: Chlorophyll fluorescence and P700 measurements provide a relatively fast and sensitive method for analysing the functional state of the photosynthetic apparatus. Salt stress resulted in practically no decrease in the values of optimal quantum yield $\left(\mathrm{F}_{\mathrm{v}} / \mathrm{F}_{\mathrm{m}}\right)$ in any of the genotypes, where the values varied between 0.74 and 0.8 irrespective of the treatment (Fig. 4). In untreated plants and under mild $(100 \mathrm{mM} \mathrm{NaCl})$ stress conditions, $\phi_{\mathrm{PSII}}$ was lower and $\phi_{\mathrm{NPQ}}$ higher in Asakaze than in barley and the $7 \mathrm{H}$ add, and no further changes in these parameters could be observed in wheat cv. Asakaze at severe stress (Fig. 5A,B). At the same time, there was a pronounced decrease in $\phi_{\text {PSII }}$ in Manas and the $7 \mathrm{H}$ add at severe stress $(300 \mathrm{mM} \mathrm{NaCl})$, which differed significantly from both the untreated control and the values recorded for Asakaze $(p \leq 0.05)$. Parallel with the reduction in $\phi_{\mathrm{PSII}}$, $\phi_{\mathrm{NPQ}}$ increased in Manas and the $7 \mathrm{H}$ add $(p \leq 0.05)$, and these parameters only partially recovered during the regeneration phase. By contrast, Asakaze showed a significant increase in $\phi_{\mathrm{PSII}}$ and decrease in $\phi_{\mathrm{NPQ}}$ during recovery phase (Fig. $5 A, B$ ). However, there were moderate differences only in the nonregulated energy dissipation $\left(\phi_{\mathrm{NO}}\right)$ between either the genotypes or the treatments (Fig. 5C).

The photochemical quantum yield of PSI ( $\left.\phi_{\text {PSI }}\right)$ did not change significantly during salt stress and recovery in Asakaze, while there was a decrease at $300 \mathrm{mM} \mathrm{NaCl}$ in Manas and the $7 \mathrm{H}$ add. However, this returned almost to the initial level during the recovery period (Fig. $5 D$ ). As indicated by the values of $\phi_{\mathrm{ND}}$ and $\phi_{\mathrm{NA}}$, the nonphotochemical quantum yields of PSI, the donor side limitation of PSI increased considerably in Manas, while the acceptor side limitation decreased at severe stress (Fig. $5 E, F$ ). These changes were slight for Asakaze, while the $7 \mathrm{H}$ add line showed moderate changes, representing a level intermediate between the wheat and barley genotypes. The differences between Asakaze and the other genotypes were statistically significant at $300 \mathrm{mM} \mathrm{NaCl}(p \leq 0.05)$.

The quantum yield of cyclic electron transport around PS I ( $\left.\phi_{\mathrm{CEF}}\right)$ was significantly higher in Asakaze than in Manas and the $7 \mathrm{H}$ add both in the control and salt treatments up to $200 \mathrm{mM}$. Salt stress was found to have little effect on $\phi_{\mathrm{CEF}}$ in Asakaze (Fig. 6), while in Manas and the $7 \mathrm{H}$ add, $\phi_{\text {CEF }}$ only reached values similar to that of Asakaze at severe stress (300 $\mathrm{mM} \mathrm{NaCl})$.

Biomass production: The root dry mass production in all the genotypes was considerable negatively affected by $300 \mathrm{mM}$ $\mathrm{NaCl}$ treatment especially in the case of Asakaze where it was decreased by $69 \%$ (Table 2). 


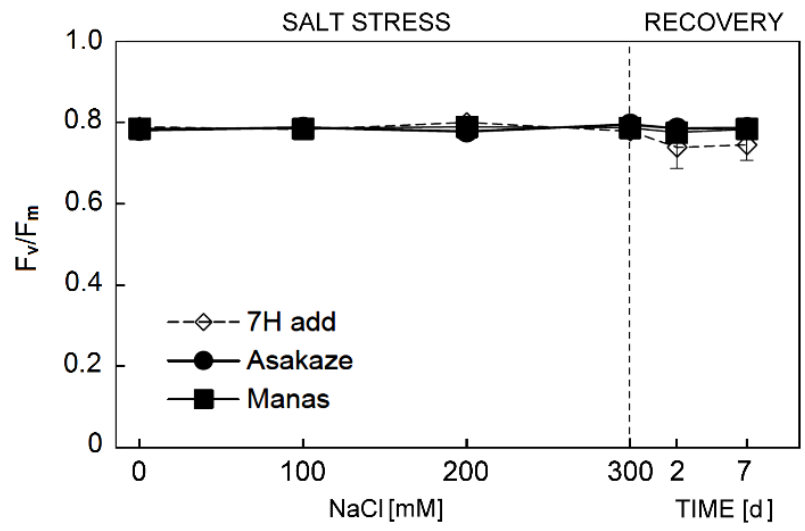

Fig. 4. Effects of increasing $\mathrm{NaCl}$ concentrations followed by seven days of regeneration on maximal quantum yield of PSII ( $\left.\mathrm{F}_{\mathrm{v}} / \mathrm{Fm}_{\mathrm{m}}\right)$ measured at $221 \mu \mathrm{mol} \mathrm{m} \mathrm{m}^{-2}$ actinic light intensity in wheat-barley $7 \mathrm{H}$ addition line (7H add), wheat (Asakaze) and barley (Manas). Each value $( \pm \mathrm{SD})$ is the mean of the data of four plants per treatment.

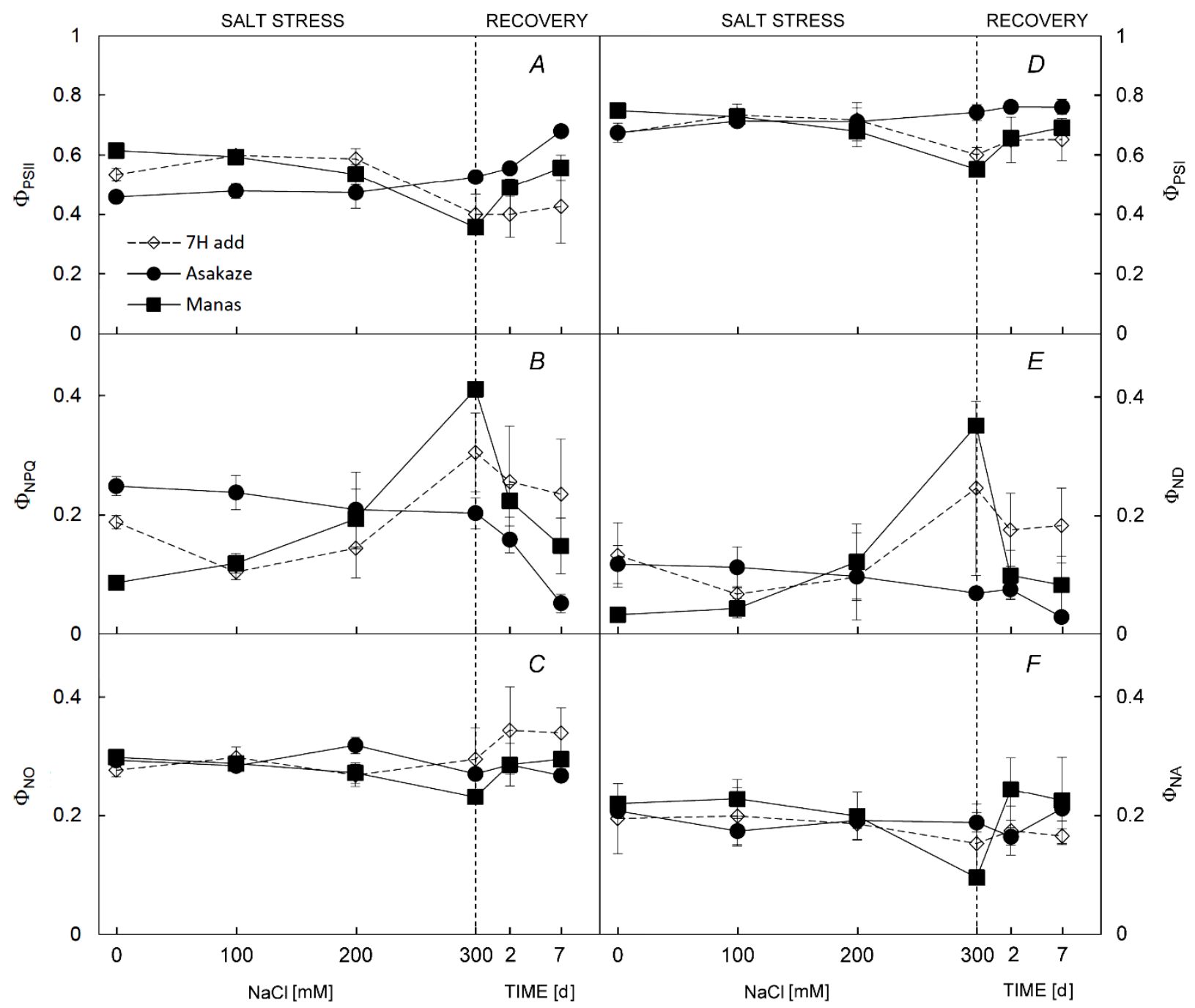

Fig. 5. Effects of increasing $\mathrm{NaCl}$ concentrations followed by seven days of regeneration on effective quantum yield of PSII photochemistry $\left(\phi_{\mathrm{PSII}}\right)(A)$, quantum yield of regulated energy dissipation $(\phi \mathrm{NPQ})(B)$, quantum yield of nonregulated energy dissipation $(\phi \mathrm{NO})$ $(C)$, photochemical quantum yield of PSI photochemistry ( $\phi$ PSI $(D)$, quantum yield of the donor side limitation of PSI $(\phi N D)(E)$, quantum yield of the acceptor side limitation of PSI $\left(\phi_{\mathrm{NA}}\right)(F)$ measured at $221 \mu \mathrm{mol} \mathrm{m}^{-2} \mathrm{~s}^{-1}$ actinic light intensity in wheat-barley $7 \mathrm{H}$ addition line ( $7 \mathrm{H}$ add), wheat (Asakaze) and barley (Manas). Each value $( \pm \mathrm{SD})$ is the mean of the data of four plants per treatment. 
By contrast, the barley and $7 \mathrm{H}$ add lost only 42 and $56 \%$ of their root dry mass production in the presence of salinity, respectively. The decrease of shoot dry mass was also more pronounced in Asakaze than in Manas and 7H add (Table 2). The salt-induced suppression of root biomass production was reflected in the increment of the shoot/root ratio in all the genotypes but the most significant change was observed in the Asakaze (data not shown).

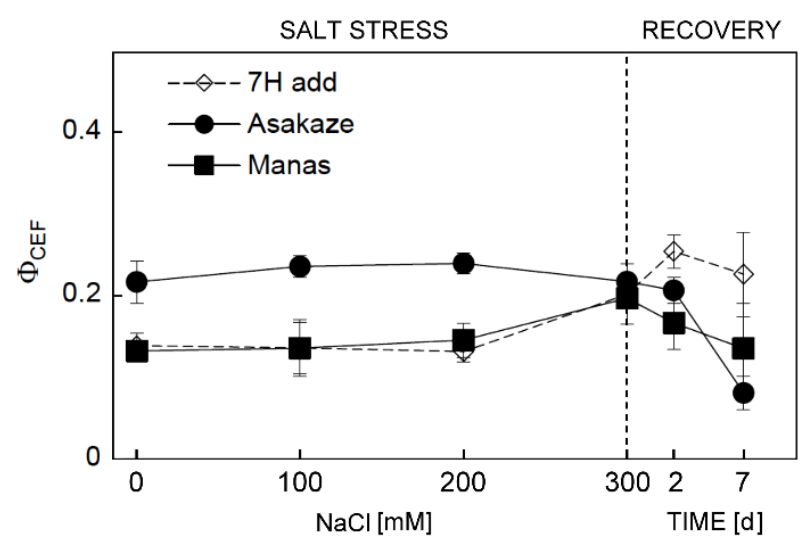

Fig. 6. Effects of increasing $\mathrm{NaCl}$ concentrations followed by seven days of regeneration on quantum yield of cyclic electron flow around PSI $\left(\phi_{\mathrm{CEF}}\right)$ measured at $221 \mu \mathrm{mol} \mathrm{m} \mathrm{m}^{-2} \mathrm{~s}^{-1}$ actinic light intensity in wheat-barley $7 \mathrm{H}$ addition line $(7 \mathrm{H}$ add), wheat (Asakaze) and barley (Manas). Each value ( $\pm \mathrm{SD})$ is the mean of the data of four plants per treatment.

Table 2. The biomass production of roots and shoots expressed in terms of dry matter for $300 \mathrm{mM} \mathrm{NaCl-treated} \mathrm{(stress)} \mathrm{and} \mathrm{control}$ plants of similar age grown in nutrient solution without $\mathrm{NaCl}$ (control). (Asakaze - wheat, Manas - barley, $7 \mathrm{H}$ add - wheat-barley $7 \mathrm{H}$ addition line). Different letters indicate statistically significant differences at $p \leq 0.05$, using Tukey's post hoc test.

\begin{tabular}{|c|c|c|c|c|}
\hline \multirow{2}{*}{ Genotypes } & \multicolumn{2}{|c|}{ Root dry mass [g per plant] } & \multicolumn{2}{|c|}{ Shoot dry mass [g per plant] } \\
\hline & Control & Stress & Control & Stress \\
\hline & 0 & $0.281^{\mathrm{d}}(3$ & $1.897^{\mathrm{b}}$ & 1 \\
\hline Man & $0.823^{\mathrm{a}}$ & $0.479^{\mathrm{b}}(58$. & $1.881^{\mathrm{b}}$ & $1.263^{\mathrm{d}}(67$ \\
\hline $7 \mathrm{H}$ add & $0.844^{\mathrm{a}}$ & $0.37^{\mathrm{c}}(43.8 \%)$ & $2.191^{\mathrm{a}}$ & $1.413^{\mathrm{c}}(64.5 \%)$ \\
\hline
\end{tabular}

\section{Discussion}

Both wheat and barley are glycophytic plants; however, barley responds better to salinity, suggesting it could be a good candidate to improve the salt tolerance of wheat (Colmer et al. 2005, 2006). It is also known that plant growth and productivity during salt stress correlate well with photosynthetic ability (James et al. 2002), which partly depends on the capacity of regulating/protecting mechanisms as reviewed by Chaves et al. (2009). In the present study the photosynthetic performance of an earlier developed 7H add (Molnár-Láng et al. 2007, 2014) was investigated under salt stress conditions to reveal how the presumed tolerance of photosynthesis to moderate salt stress in barley cv. Manas (Dulai et al. 2010) is manifested in the genetic background of wheat. In these experiments, deeper knowledge was obtained about the mechanisms responsible for the tolerance of photosynthesis to various levels of salt stress and of the regeneration capacity after salt elimination. Fluorescence in situ hybridization demonstrated that, besides the whole wheat genome the $7 \mathrm{H}$ barley chromosome was present in the $7 \mathrm{H}$ add (Fig. 1), so the manifestation of salt tolerance traits was not limited by the lack of the $7 \mathrm{H}$ barley chromosome.

Several photosynthetic processes are modified during salt stress. Prior to the accumulation of toxic ions, moderate salt stress also has osmotic effects, influencing the water balance, stomatal behaviour and net carbon fixation processes of plants (Munns 2002, Munns and Tester 2008). In most cases stomatal closure can be observed, as indicated by a decrease in $g_{\mathrm{s}}$ (Centritto et al. 2003). While RWC decreased moderately in Manas and the $7 \mathrm{H}$ add, wheat cv. Asakaze exhibited a dramatic drop in $g_{\mathrm{s}}$ even during mild stress (Fig. $2 A, B$ ). Although stomatal closure is the most efficient way of reducing water loss, allowing water saving and improving water use efficiency (Chaves et al. 2009), Manas and the $7 \mathrm{H}$ add were able to avoid drastic water losses, as well as exhibiting only a moderate decrease in $g_{\mathrm{s}}$. These results show that Manas and the $7 \mathrm{H}$ add were able to maintain their water status at a level similar to that of Asakaze without intense stomatal closure. This suggests that an efficient osmoregulation mechanism exists in these genotypes, as also demonstrated by Darkó et al. (2015). Teulat et al. (1998) also suggested that the 7H homoeologous chromosome played a role in osmotic adjustment in 
barley. These results indicate that barley and the $7 \mathrm{H}$ add are better able to adjust osmotic pressure, contributing to efficient water uptake and tolerance of moderate salt stress.

As the stomatal closure not only affects the regulation of water loss but also restricts $\mathrm{CO}_{2}$ diffusion into the leaves (Chaves et al. 2009), thus influencing mesophyll conductance and photosynthetic $\mathrm{CO}_{2}$ fixation (Centritto et al. 2003), the maintenance of adequate photosynthesis may require relatively high $g_{\mathrm{s}}$ (James et al. 2008). In Asakaze $P_{\mathrm{N}}$ decreased substantially as $g_{\mathrm{s}}$ fell even at a moderate stress level, while it hardly differed from the control in Manas and the $7 \mathrm{H}$ add, which responded with less intense stomatal closure. These results show that barley and the $7 \mathrm{H}$ add were able to maintain photosynthesis parallel with moderate stomatal closure as indicated by the relatively high $g_{\mathrm{s}}$. These genotypes were able to prevent significant water loss due to their better capacity for osmotic adjustment. It seems that plants responding to mild or moderate salt stress with relatively low stomatal closure, in parallel with improved osmotic adjustment, follow an efficient strategy for sustaining photosynthetic activity. These results are in accordance with earlier results where the photosynthetic rate was reported to be a good tool for discriminating between salt-tolerant and susceptible plants (Belkhodja et al. 1999).

Many authors suggest that stomatal and nonstomatal factors may contribute to the inhibition of $P_{\mathrm{N}}$ under salt stress (Centritto et al. 2003, Hu et al. 2013). In nonstressed but light-saturated $\mathrm{C}_{3}$ plant $P_{\mathrm{N}}$ does not reach the maximum level which would otherwise be measurable at saturating $\mathrm{CO}_{2}$ concentration ( $P_{\mathrm{Nmax}}$, Lawlor and Cornic 2002). As long as stomatal limitation is exclusive in the inhibition of $P_{\mathrm{N}}$, exposuring leaves to saturating $\mathrm{CO}_{2}$ should be effective in restoring $P_{\text {Nmax }}$ in salt-stressed plants. As demonstrated in Fig. $3 A, P_{\text {Nmax }}$ was fully restored at moderate salt stress in Manas and the $7 \mathrm{H}$ add, indicating that the regulation of $P_{\mathrm{N}}$ was definitely affected by stomatal limitation. Although $P_{\mathrm{Nmax}}$ was not fully recovered in Asakaze, the strong stomatal closure and decrease in $C_{\mathrm{i}}$ indicate that stomatal limitation is also responsible to a considerable extent for the inhibition of $P_{\mathrm{N}}$ in Asakaze. This was also manifested in the $\mathrm{L}_{\mathrm{s}}$ values calculated on the basis of $C_{\mathrm{i}} v . P_{\mathrm{N}}$ curves (Fig. $3 B$ ) as described by Lawlor (2002). Since $P_{\mathrm{Nmax}}$ is not fully restored by saturating $\mathrm{CO}_{2}, P_{\mathrm{N}}$ must also be influenced by the processes responsible for nonstomatal limitation $\left(\mathrm{L}_{\mathrm{ns}}\right)$. $P_{\mathrm{Nmax}}$ decreased and $\mathrm{L}_{\mathrm{ns}}$ increased in Asakaze parallel with the severity of salt stress (Fig. 3) even in the moderate treatment, indicating the increased importance of mesophyllic or metabolic factors in the restriction of photosynthesis, which were negligible for Manas and the $7 \mathrm{H}$ add. Consequently, the susceptibility of photosynthesis to salt is more pronounced in this wheat genotype at moderate stress level than in barley or the $7 \mathrm{H}$ add, where the dominant role of stomatal limitation was observed. Very similar results were obtained when the sensitivity of photosynthetic $\mathrm{CO}_{2}$ fixation to stress was estimated as the ability to restore the maximal assimilation rate or by calculating limitations on the basis of $C_{\mathrm{i}} v$. $P_{\mathrm{N}}$ curves (Lawlor 2002).

There are thought to be several biochemical (metabolic) and diffusional factors in the background of nonstomatal limitation (Lawlor and Cornic 2002, Chaves et al. 2009, Flexas et al. 2004). In the present case, the rapid decline in $g_{\text {s }}$ caused in Asakaze by the initial salinity resulted in a decrease in $\mathrm{CO}_{2}$ availability for carboxylation. Thus, it may be that the rapid, substantial increase in stomatal resistance in response to the initial osmotic shock caused by $\mathrm{NaCl}$ led indirectly to the nonstomatal limitation observed at $200 \mathrm{mM} \mathrm{NaCl}$ via a gradual reduction in $\varepsilon$ (Table 1). As reported by Downton et al. (1988) conclusions drawn on the basis of $C_{\mathrm{i}}$ may be uncertain due to the patchy stomatal closure (Buckley et al. 1997) and the estimation of $C_{\mathrm{i}}$ can be biased also by the cuticular transpiration (Boyer et al. 1997). However, since the decrease in $C_{\mathrm{i}}$ was not proportional to the strong drop in $g_{\mathrm{s}}$ (Fig. $2 B, C$ ) possibly a mesophyllic diffusion barrier or an alternative electron sink might operate in Asakaze in the early stages of stress, influencing the $\mathrm{CO}_{2}$ level in the intercellular spaces. It was suggested by Kozaki and Takeba (1996) and Chaves et al. (2009), that photorespiration might also be involved in the protection of the photosynthetic apparatus when intense stomatal closure restricts $\mathrm{CO}_{2}$ diffusion into the leaves. In this case, protective mechanisms may be important even at normal light intensity.

When salt stress becomes severe and $\mathrm{CO}_{2}$ assimilation is significantly disturbed, the role of nonstomatal factors in the limitation of photosynthesis usually becomes more pronounced (Brugnoli and Lauteri 1991; Qin et al. 2010). As can be seen in Fig. 2D, $P_{\mathrm{N}}$ was significantly inhibited at $300 \mathrm{mM} \mathrm{NaCl}$ in all the genotypes. The significant increase in $C_{\mathrm{i}}$ also indicated the importance of nonstomatal factors (Qin et al. 2010) in Manas and to some extent in the $7 \mathrm{H}$ add. $\mathrm{L}_{\mathrm{ns}}$ was substantially higher in Manas than in Asakaze or the $7 \mathrm{H}$ add. It is interesting to note, that the salt-induced changes in nonstomatal limitation in the $7 \mathrm{H}$ add were similar to those recorded for Manas at moderate salinity levels (up to $200 \mathrm{mM}$ $\mathrm{NaCl}$ ), but resembled those in Asakaze in the case of severe salt stress (at $300 \mathrm{mM} \mathrm{NaCl}$ ). Consequently, the overall photosynthetic performance of $7 \mathrm{H}$ add appears to exhibit the better traits of the parental genotypes under both moderate and severe stress, although this is not true of all the processes involved in photosynthesis.

Photochemical and electron transport processes may also affect photosynthetic $\mathrm{CO}_{2}$ fixation during salt stress both in wheat and barley, but the contribution of these processes to the limitation of $\mathrm{CO}_{2}$ assimilation usually depends on the duration/intensity of the salt treatment (Kalaji et al. 2011). In the present work the level of salt stress increased slowly and gradually. The optimal quantum yield $\left(\mathrm{F}_{\mathrm{v}} / \mathrm{F}_{\mathrm{m}}\right)$ and the quantum yield of nonregulated energy dissipation $\left(\phi_{\mathrm{NO}}\right)$ were practically unaffected by salt stress even at $300 \mathrm{mM} \mathrm{NaCl}$ (Figs. 4, 5C). These results suggest that salinity had no noticeable effect on the capacity of primary charge separation, and no PSII damage was observed in the range of treatment applied as also reported by Hanachi et al. (2014). As shown by the slight changes observed in $\phi_{\text {PSII }}$ values, electron 
transport processes were also unlimited in all the genotypes up to $200 \mathrm{mM} \mathrm{NaCl}$. It is unlikely that the salt sensitivity of PSII or the salt-induced downregulation of electron transport processes is the main reason for the decrease in the assimilation rate or for the nonstomatal limitation observed in Asakaze. This is supported by the fact that $\phi_{\text {PSII }}$ did not decrease further under severe stress in this genotype. Since $\phi_{\text {PSII }}$ was lower in Asakaze than in Manas or the $7 \mathrm{H}$ add in untreated plants and at mild salt stress, parallel with higher $\phi_{\mathrm{NPQ}}$, it is likely that the PSII activity was originally slightly downregulated by unknown mechanisms in Asakaze as compared to Manas and the $7 \mathrm{H}$ add. Although, further investigations are required to reveal the reason for this phenomenon, it is evident that the difference in fluorescence parameters observed between Asakaze and Manas is not a consequence of the salt treatment. In the case of barley and the $7 \mathrm{H}$ add, severe salt stress caused a significant decrease in $\phi_{\text {PSII }}$ (more than 40 and $25 \%$ of the original activity was lost, respectively), indicating that electron transport processes were downregulated in these genotypes. Parallel with this, photoprotective mechanisms were more intensely accelerated in these lines than in Asakaze, as indicated by the $\phi_{\mathrm{NPQ}}$ and $\phi_{\mathrm{ND}}$ values (Fig. $5 B, E$ ). These processes compete with primary photochemistry for the absorbed excitation energy, leading to a decrease in $\phi_{\text {PSII }}$ (Genty et al. 1989) and an increase in nonradiative energy dissipation in the light-harvesting complexes (Horton and Ruban 2005, Chaves et al. 2009). Considering that the acceptor side limitation did not increase, as reflected in $\phi_{\mathrm{NA}}$, while $\mathrm{L}_{\mathrm{ns}}$ increased substantially (Figs. $3 C, 5 F$ ) the downregulation of PSII-driven electron transport might be partly responsible for the nonstomatal limitation of photosynthesis in Manas and the $7 \mathrm{H}$ add at severe salt stress.

Parallel with linear electron transport, electrons may also follow a cyclic route, driven solely by PSI and known as cyclic electron flow (CEF), which generate $\Delta \mathrm{pH}$ across the thylakoid membranes leading to the formation of ATP but not NADPH, thus preventing the over-reduction of the acceptor side of PSI. CEF is considered to be essential for efficient photosynthesis even if plants are grown in under stress-free conditions (Munekage et al. 2004). Several studies have shown that it may be stimulated by water deficit (Golding and Johnson 2003, Dulai et al. 2014) or salt stress (Lu et al. 2008). $\mathrm{CEF}$ is also thought to support the regulation of light-harvesting processes via the enhancement of NPQ, thereby contributing to the protection of PSII (Golding and Johnson 2003). The higher values of $\phi_{\mathrm{NPQ}}$ and $\phi_{\mathrm{CEF}}(\mathrm{Figs}$. $5 B, 6)$ in the leaves of Manas and the $7 \mathrm{H}$ add compared to the control at severe stress suggest that CEF may help to prevent the over-reduction of the electron transport chain and subsequent oxidative damage. This is confirmed by the fact that the acceptor side limitation of PSI, represented by $\phi_{\mathrm{NA}}$, did not increase at this stage of stress. Interestingly, the values of $\phi_{\mathrm{NPQ}}$ and the activity of CEF were originally higher in Asakaze than in Manas and the $7 \mathrm{H}$ add, and were hardly influenced by salt treatment.

When the genotypes were compared, both $\mathrm{CO}_{2}$ assimilation and photosynthetic electron transport processes showed a similar tendency in barley and the $7 \mathrm{H}$ add, but differed in wheat. In the former genotypes, the slight decrease of $\mathrm{CO}_{2}$ assimilation and stomata closure was accompanied with slight changes of NPQ under mild and moderate salt stress induced by 100 or $200 \mathrm{mM} \mathrm{NaCl}$. In the case of Asakaze, the fluorescence induction parameters were practically unaffected by salt stress, but the assimilation rate decreased significantly even at mild (100 mM) salinity. At severe $(300 \mathrm{mM})$ salt stress $\mathrm{CO}_{2}$ fixation and NPQ changed significantly in Manas and the $7 \mathrm{H}$ add, so the $\mathrm{CO}_{2}$ assimilation rate and $g_{\mathrm{s}}$ parameters became similar to that of Asakaze.

The ability to recover from stress-induced downregulation or injury may depend both on the level of stress-induced damage (Chaves et al. 2009) and on the sensitivity of the plants. When photosynthesis is mainly limited by stomatal factors, $\mathrm{CO}_{2}$ fixation may recover to the normal level relatively rapidly after the elimination of the stress via the restoration of $g_{\mathrm{s}}$, as observed in the case of Asakaze in the present experiments, where $76 \%$ of the original activity was restored by the second day. By contrast, when $\mathrm{L}_{\mathrm{n}}$ is the dominant factor and key photosynthetic processes are affected, the regeneration capacity of $\mathrm{CO}_{2}$ fixation may slow down, as found in Manas, where the greatest extent of $\mathrm{L}_{\mathrm{ns}}$ was recorded. However, complete regeneration was recorded in Manas by the $7^{\text {th }}$ day. In the case of $7 \mathrm{H}$ add, slow regeneration was observed throughout the regeneration period. In agreement with these results, Kirschbaum (1988) also demonstrated biphasic recovery from severe water stress. It has been suggested that the maintenance of photoprotective mechanisms is responsible for the slow or incomplete recovery of $\mathrm{CO}_{2}$ assimilation (Chaves et al. 2009). It should also be mentioned that the $7 \mathrm{H}$ add started to head during the third week of the salt treatment and showed moderate leaf senescence. This earliness, possibly induced by salt stress, might also have retarded the recovery process and may be related to the relatively moderate stomatal closure and osmotic adjustment, as indicated by González et al. (1999).

The sensitivity of photosynthetic capacity to moderate salt stress was manifested as a considerable reduction in dry matter production in Asakaze, where the root biomass production in particular was strongly inhibited (Table 2). Although, the relationship between the net photosynthesis of leaves and growth or biomass production is not simple and often could be indirect (Flood et al. 2011) the more promising dry matter production for Manas and 7H add suggests better tolerance to moderate salinity of the latter genotypes.

In conclusion, the results proved that the $7 \mathrm{H}$ add was able to maintain its photosynthetic rate under moderate salt stress. This line seems to respond to moderate salt stress with low stomatal closure which may result in an efficient strategy for sustaining photosynthetic activity based on osmotic adjustment, as found by Darkó et al. (2015). As the better tolerance 
of photosynthesis to moderate salt stress exhibited by the barley parent cv. Manas appears to be manifested in the $7 \mathrm{H}$ add, it is a good candidate for improving the tolerance of bread wheat to salt stress.

\section{References}

Allakhverdiev S.I., Nishiyama Y., Miyairi S. et al.: Salt stress inhibits the repair of photodamaged photosystem II by suppressing the transcription and translation of psbA genes in Synechocystis. - Plant Physiol. 130: 1443-1453, 2002.

Apostolova E.L., Dobrikova A.G., Ivanova P.I. et al.: Relationship between the organization of the PSII supercomplex and the functions of the photosynthetic apparatus. - J. Photoch. Photobio. B. 83: 114-122, 2006.

Asada K.: Production and scavenging of reactive oxygen species in chloroplasts and their functions. - Plant Physiol. 141: 391-396, 2006.

Ashraf M., Harris P.J.C.: Photosynthesis under stressful environments: An overview. - Photosynthetica 51: 163-190, 2013.

Belkhodja R., Morales F., Abadía A. et al.: Effects of salinity on chlorophyll fluorescence and photosynthesis of barley (Hordeum vulgare L.) grown under a triple-line-source sprinkler system in the field. - Photosynthetica 36: 375-387, 1999.

Boyer J.S., Wong S.C., Farquhar D.F.: $\mathrm{CO}_{2}$ and water vapor exchange across leaf cuticle (epidermis) at various water potentials. - Plant Physiol. 114: 185-191, 1997.

Brugnoli E., Lauteri M.: Effects of salinity on stomatal conductance, photosynthetic capacity, and carbon isotope discrimination of salttolerant (Gossypium hirsutum L.) and salt-sensitive (Phaseolus vulgaris L.) C 3 nonhalophytes. - Plant Physiol. 95: 628-635, 1991.

Buckley T.N., Farquhar G.D., Mott K.A.: Qualitative effects of patchy stomatal conductance distribution features on gas-exchange calculations. - Plant Cell Environ. 20: 867-880, 1997.

Centritto M., Loreto F., Chartzoulakis K.: The use of low $\left[\mathrm{CO}_{2}\right]$ to estimate diffusional and nondiffusional limitations of photosynthetic capacity of salt-stressed olive saplings. - Plant Cell Environ. 26: 585-594, 2003.

Chaves M.M., Flexas J., Pinheiro C.: Photosynthesis under drought and salt stress: regulation mechanisms from whole plant to cell. Ann. Bot. 103: 551-560, 2009.

Colmer T.D., Munns R., Flowers T.J.: Improving salt tolerance of wheat and barley: future prospects. - Aust. J. Exp. Agr. 45: 1425$1443,2005$.

Colmer T.D., Flowers T.J., Munns R.: Use of wild relatives to improve salt tolerance in wheat. - J. Exp. Bot. 57: 1059-1078, 2006.

da Silva E.N., Ribeiro R.V., Ferreira-Silva S.L. et al.: Salt stress induced damages on the photosynthesis of physic nut young plants. Sci. Agric. 68: 62-68, 2011.

Darkó É., Janda T., Majláth I. et al.: Salt stress response of wheat-barley addition lines carrying chromosomes from the winter barley "Manas". - Euphytica 203: 491-504, 2015.

Downton W.J.S., Loveys B.R., Grant W.J.R.: Stomatal closure fully accounts for the inhibition of photosynthesis by abscisic acid. New Phytol. 108: 263-266, 1988.

Dulai S., Molnár I., Háló B. et al.: Photosynthesis in the 7H Asakaze Komugi/Manas wheat/barley addition line during salt stress. Acta Agron. Hung. 58: 367-376, 2010.

Dulai S., Molnár I., Molnár-Láng M.: Changes of photosynthetic parameters in wheat/barley introgression lines during salt stress. Acta Biol. Szeged 55: 73-75, 2011.

Dulai S., Molnár I., Szopkó D. et al.: Wheat-Aegilops biuncialis amphiploids have efficient photosynthesis and biomass production during osmotic stress. - J. Plant Physiol. 171: 509-517, 2014.

Everard J.D., Gucci R., Kann S.C. et al.: Gas exchange and carbon partitioning in the leaves of celery (Apium graveolens L.) at various levels of root zone salinity. - Plant Physiol. 106: 281-292, 1994.

Flexas J., Bota J., Loreto F. et al.: Diffusive and metabolic limitations to photosynthesis under drought and salinity in $\mathrm{C}_{3}$ plants. - Plant Biol. 6: 269-279, 2004.

Flood P.J., Harbinson J., Aarts M.G.M.: Natural genetic variation in plant photosynthesis. Trends Plant Sci. 16: 327-335, 2011.

Genty B., Briantais J.M., Baker N.R.: The relationship between the quantum yield of photosynthetic electron transport and quenching of chlorophyll fluorescence. - Biochim. Biophys. Acta 990: 87-92, 1989.

Golding A.J., Johnson G.N.: Down-regulation of linear and activation of cyclic electron transport during drought. - Planta 218: 107$114,2003$.

González A., Martin I., Ayerbe L.: Barley yield in water-stress conditions. The influence of precocity, osmotic adjustment and stomatal conductance. - Field Crop. Res. 62: 23-34, 1999.

Hanachi S., Van Labeke M.C., Mehouachi T.: Application of chlorophyll fluorescence to screen eggplant (Solanum melangenum L.) cultivars for salt tolerance. - Photosynthetica 52: 57-62, 2014.

Horton P., Ruban A.: Molecular design of the photosystem II light-harvesting antenna: photosynthesis and photoprotection. - J. Exp. Bot. 56: 365-373, 2005.

Hu T., Yi H., Hu L. et al.: Stomatal and metabolic limitations to photosynthesis resulting from $\mathrm{NaCl}$ stress in perennial ryegrass genotypes differing in salt tolerance. - J. Am. Soc. Hortic Sci. 138: 350-357, 2013.

Huang W., Zhang S.B., Cao K.F.: Stimulation of cyclic electron flow during recovery after chilling-induced photoinhibition of PSII. Plant Cell Physiol. 1: 1922-1928, 2010.

James R.A., Rivelli A.R., Munns R., von Caemmerer S.: Factors affecting $\mathrm{CO}_{2}$ assimilation, leaf injury and growth in salt-stressed durum wheat. - Funct. Plant Biol. 29: 1393-1403, 2002.

James R. A., von Caemmerer S., Condon A.G. et al.: Genetic variation in tolerance to the osmotic stress component of salinity stress in durum wheat. - Funct. Plant Biol. 35: 111-123, 2008. 
Kalaji H.M., Govindjee Bosa K., Koscielniak J., Zuk-Golaszewska K.: Effects of salt stress on photosystem II efficiency and $\mathrm{CO}_{2}$ assimilation of two Syrian barley landraces. -Environ. Exp. Bot. 73: 64-72, 2011.

Kirschbaum M.U.F.: Recovery of photosynthesis from water stress in Eucalyptus pauciflora - a process in two stages. - Plant Cell Environ. 11: 685-694, 1988.

Klughammer C., Schreiber U.: An improved method, using saturating light pulses for the determination of photosystem I quantum yield via $\mathrm{P} 700^{+}$absorbance changes at $830 \mathrm{~nm}$. - Planta 192: 261-268, 1994.

Klughammer C., Schreiber U.: Complementary PS II quantum yields calculated from simple fluorescence parameters measured by PAM fluorometry and the saturation pulse method. - PAM Application Notes 1: 11-14, 2008a.

Klughammer C., Schreiber U.: Saturation pulse method for assessment of energy conversion in PS I. - PAM Application Notes 1: 27$35,2008 \mathrm{~b}$

Kozaki A., Takeba G.: Photorespiration protects C3 plants from photooxidation. - Nature 384: 557-560, 1996.

Lawlor D.W.: Limitation to photosynthesis in water-stressed leaves: Stomata vs. Metabolism and the role of ATP. - Ann. Bot.-London 89: 871-885, 2002.

Lawlor D.W., Cornic G.: Photosynthetic carbon assimilation and associated metabolism in relation to water deficits in higher plants. Plant Cell Environ. 25: 275-294, 2002.

Lu K.X., Yang Y., He Y., Jiang D.A.: Induction of cyclic electron flow around photosystem 1 and state transition are correlated with salt tolerance in soybean. - Photosynthetica 46: 10-16, 2008.

Molnár-Láng M., Linc G., Logojan A., Sutka J.: Production and meiotic pairing behaviour of new hybrids of winter wheat (Triticum aestivum) $\times$ winter barley (Hordeum vulgare). - Genome 43: 1045-1054, 2000.

Molnár-Láng M., Szakács É., D Nagy E.: Development and molecular cytogenetic identification of new winter wheat/winter barley disomic addition lines. - In: Buck H.T., Nisi J.E., Salomón N. (ed.): Wheat Production in Stressed Environments. Developments in Plant Breeding. Pp. 707-713. Springer, Dordrecht 2007.

Molnár-Láng M., Kruppa K., Cseh A. et al.: Identification and phenotypic description of new wheat-six-rowed winter barley disomic additions. - Genome 55: 302-311, 2012.

Molnár-Láng M., Linc G., Szakács É.: Wheat-barley hybridization - the last forty years. Euphytica 195: 315-329, 2014.

Munekage Y., Hashimoto M., Miyake C. et al.: Cyclic electron flow around photosystem I is essential for photosynthesis. - Nature 429 : 579-582, 2004.

Munns R.: Comparative physiology of salt and water stress. - Plant Cell Environ. 25: 239-250, 2002.

Munns R., James R.A., Lauchli A.: Approaches to increasing the salt tolerance of wheat and other cereals. - J. Exp. Bot. 57: 1025-1043, 2006.

Munns R., Tester M.: Mechanisms of salinity tolerance. - Annu. Rev. Plant Biol. 59: 651-681, 2008.

Muranaka S., Shimizu K., Kato M.: A salt-tolerant cultivar of wheat maintains photosynthetic activity by suppressing sodium uptake. - Photosynthetica 40: 509-515, 2002.

Nagy Z., Galiba G.: Drought and salt tolerance are not necessarily linked: a study on wheat varieties differing in drought resistance under consecutive water and salinity stresses. -J. Plant Physiol. 145: 168-174, 1995.

Pfanz H., Vodnik D., Wittmann C. et al:: Photosynthetic performance $\left(\mathrm{CO}_{2}\right.$-compensation point, carboxylation efficiency, and net photosynthesis) of timothy grass (Phleum pratense L.) is affected by elevated carbon dioxide in postvolcanic mofette areas. -Environ. Exp. Bot. 61: 41-48, 2007.

Pitman M.G., Läuchli A.: Global impact of salinity and agricultural ecosystems. - In: Läuchli A., Lüttge U. (ed.): Salinity: EnvironmentPlants-Molecules. Pp. 3-20. Kluwer, Dordrecht 2002.

Qin J., Dong W.Y., He K.N. et al.: NaCl salinity induced changes in water status, ion contents and photosynthetic properties of Shepherdia argentea (Pursh) Nutt. seedlings. - Plant Soil Environ. 56: 325-332, 2010.

Qiu N., Lu Q., Lu C.: Photosynthesis, photosystem II efficiency and the xanthophyll cycle in the salt-adapted halophyte Atriplex centralasiatica. - New Phytol. 159: 479-486, 2003.

Rahnama A., Poustini K., Tavakkol-Afshari R., Tavakoli A.: Growth and stomatal responses of bread wheat genotypes in tolerance to salt stress. - World Acad. Sci. Eng. Technol. 71: 14-19, 2010.

Sanada Y., Ueda H., Kuribayashi K. et al.: Novel light-dark change of proline levels in halophyte (Mesembryanthemum crystallinum L.) and glycophyte (Hordeum vulgare L. and Triticum aestivum L.) leaves and roots under salt stress. - Plant Cell Physiol. 36: 965 970, 1995.

Stepien P., Klobus G.: Water relations and photosynthesis in Cucumis sativus L. leaves under salt stress. - Biol. Plantarum 50: 610616,2006

Sudhir P., Murthy S.D.S.: Effects of salt stress on basic processes of photosynthesis. - Photosynthetica 42: 481-486, 2004.

Sudhir P., Pogoryelov D., Kovács L. et al.: The effects of salt stress on photosynthetic electron transport and thylakoid membrane proteins in the cyanobacterium Spirulina platensis. - J. Biochem. Mol. Biol. 38: 481-485, 2005.

Tester M., Davenport R.J.: $\mathrm{Na}^{+}$tolerance and $\mathrm{Na}^{+}$transport in higher plants. - Ann. Bot. 91: 503-527, 2003.

Teulat B., This D., Khairallah M. et al.: Several QTLs involved in osmotic-adjustment trait variation in barley (Hordeum vulgare L.). - Theor. Appl. Genet. 96: 688-698, 1998.

van Kooten O., Snel J.F.H.: The use of chlorophyll fluorescence nomenclature in plant stress physiology. - Photosynth. Res. 25: 147150,1990

von Caemmerer S., Farquhar G.D.: Some relationships between the biochemistry of photosynthesis and the gas exchange of leaves. Planta 153: 376-387, 1981 